\title{
Behavior of Shear Link of WF Section with Diagonal Web Stiffener of Eccentrically Braced Frame (EBF) of Steel Structure
}

\author{
Yurisman, Bambang Budiono, Muslinang Moestopo \& Made Suarjana \\ Civil Engineering Department, Institute of Technology Bandung. \\ Email: Yurisman_pdg@yahoo.com
}

\begin{abstract}
This paper presents results of numerical and experimental study of shear link behavior, utilizing diagonal stiffener on web of steel profile to increase shear link performance in an eccentric braced frame (EBF) of a steel structure system. The specimen is to examine the behavior of shear link by using diagonal stiffener on web part under static monotonic and cyclic load. The cyclic loading pattern conducted in the experiment is adjusted according to AISC loading standards 2005. Analysis was carried out using non-linear finite element method using MSC/NASTRAN software. Link was modeled as CQUAD shell element. Along the boundary of the loading area the nodal are constraint to produce only one direction loading. The length of the link in this analysis is $400 \mathrm{~mm}$ of the steel profile of WF 200.100. Important parameters considered to effect significantly to the performance of shear link have been analyzed, namely flange and web thicknesses, thickness and length of web stiffener, thickness of diagonal stiffener and geometric of diagonal stiffener. The behavior of shear link with diagonal web stiffener was compared with the behavior of standard link designed based on AISC 2005 criteria. Analysis results show that diagonal web stiffener is capable to increase shear link performance in terms of stiffness, strength and energy dissipation in supporting lateral load. However, differences in displacement ductility's between shear links with diagonal stiffener and shear links based on AISC standards have not shown to be significant. Analysis results also show thickness of diagonal stiffener and geometric model of stiffener to have a significant influence on the performance of shear links. To perform validation of the numerical study, the research is followed by experimental work conducted in Structural Mechanic Laboratory Center for Industrial Engineering ITB. The Structures and Mechanics Lab rotary PAU-ITB. The experiments were carried out using three test specimens with model and dimension identical to the model in the numerical study. Experimental testing apparently has shown results of the same behavior as predicted in the numerical study. However, when it is compared to the shape of the hysterical curve, a slight difference is apparent. This is due to the influence of stiffness of bolt joints and the supports which is difficult to model precisely in the numerical studies.
\end{abstract}

Keywords: cyclic loading; diagonal web stiffener; ductility; energy dissipation; monotonic loading; shear link; stiffness; strength. 


\section{Introduction}

Indonesia is located in a tectonic area with high occurrences of earthquakes. This has resulted in many efforts to reduce risk created by this situation. Most fatalities due to earthquakes are caused by building collapse. To prevent such risks, designs of earthquake resistant buildings are based on a prevention concept where in the case of a major earthquake, buildings may experience damages, and however people inside the building must remain unharmed. Based on Indonesia's National Standard (SNI) for earthquake resistant buildings is designed by allowing the ductility concept. Based on this concept, in the event of a major earthquake, certain elements of a structure may undergo plastification. This plastification is a mechanism to dissipate earthquake energy on the structure, preventing the structure to collapse. To allow this, elements need to be designed to experience a stabile inelastic deformation during a major earthquake.

A steel structure is regarded as an earthquake resistant structure with a remarkable performance. This is due to unique characteristics of steel. By relying on the ductility and high strength characteristics, steel is suitable to be applied in areas with high seismic activity. Under the steel structure's category, there are three systems which are resistant to earthquakes, (1) Moment Resisting Frame (MRF); (2) Concentrically Braced Frame (CBF); and (3) Eccentrically Braced Frame (EBF). MRF has superiority in energy dissipation ability to achieve required ductility, however this structure lacks of strength and stiffness resulting the requirement of a larger surface area and an expensive double plate panel zone to fulfill drift requirements. CBF efficiently fulfills deformation limits through its framework action; however the stability in the mechanism of energy dissipation is limited [1]. The limitation of both structures has resulted in the development of a new structure system named Eccentrically Braced Frame (EBF) structures. The difference in the three steel structural systems is shown in Figure 1.

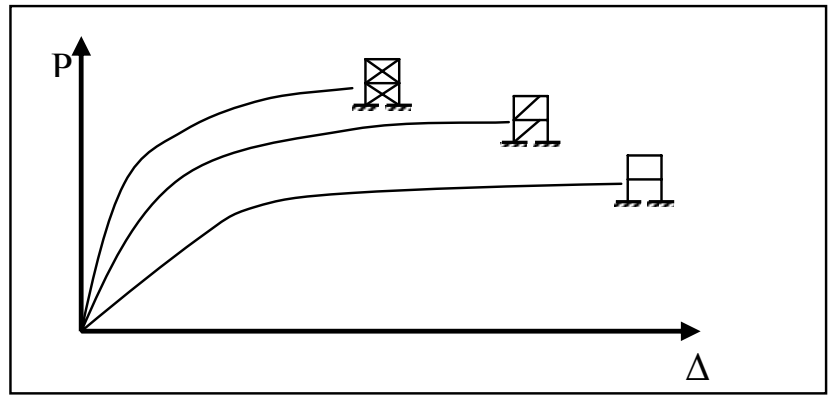

Figure 1 Behavior Differences in Three Steel Structure's System [2]. 


\section{The Objective of Research}

The article presented in this paper is part of a Doctor's student research conducted in Civil Engineering Department of Institute of Technology Bandung (ITB) division of structural engineering. The specimen of the study is to obtain an EBF structure with maximum performance through increasing performance of link elements. To achieve the specimen, this study is aims to: 1) Understand mechanism of earthquake energy dissipation in eccentric braced frame steel framework structure. 2) Determine parameters which significantly affect link element behavior in eccentric braced frame, 3) examine each parameter in resulting an improvement of performance link, 4) examine the usage of diagonally placed web stiffeners on link element increasing link performance in EBF.

\section{$3 \quad$ Literature Study}

\subsection{General Overview of Eccentric Braced Frame (EBF) Structure System}

Eccentric braced frame (EBF) structure system is a development from the two previous lateral force resistant systems, which are MRF and CBF. MRF has superiority as it is very ductile and it capable of for large energy dissipation capacity, but low in stiffness, while CBF has high stiffness but a small energy dissipation capacity. Therefore EBF was developed to perfect both MRF and CBF systems. Figure 2 illustrates forms of EBF system which are generally applied [3].

EBF system joins each advantage from both structure systems, and decrease the weakness. The EBF characteristics are: 1) has a high elastic stiffness; 2) has a stable inelastic response under lateral cyclic loading; 3) has a high ductility and energy dissipation ability.

In EBF, absorbance of earthquake energy is carried out through a mechanism of plastic joint formation on link elements. Link elements are part of the beam which is assigned to dissipate energy in the event of a large earthquake. Plastic hinges occurring on link elements can be in a form of shear or flexural yielding. The type of yielding is dependent on link length. 


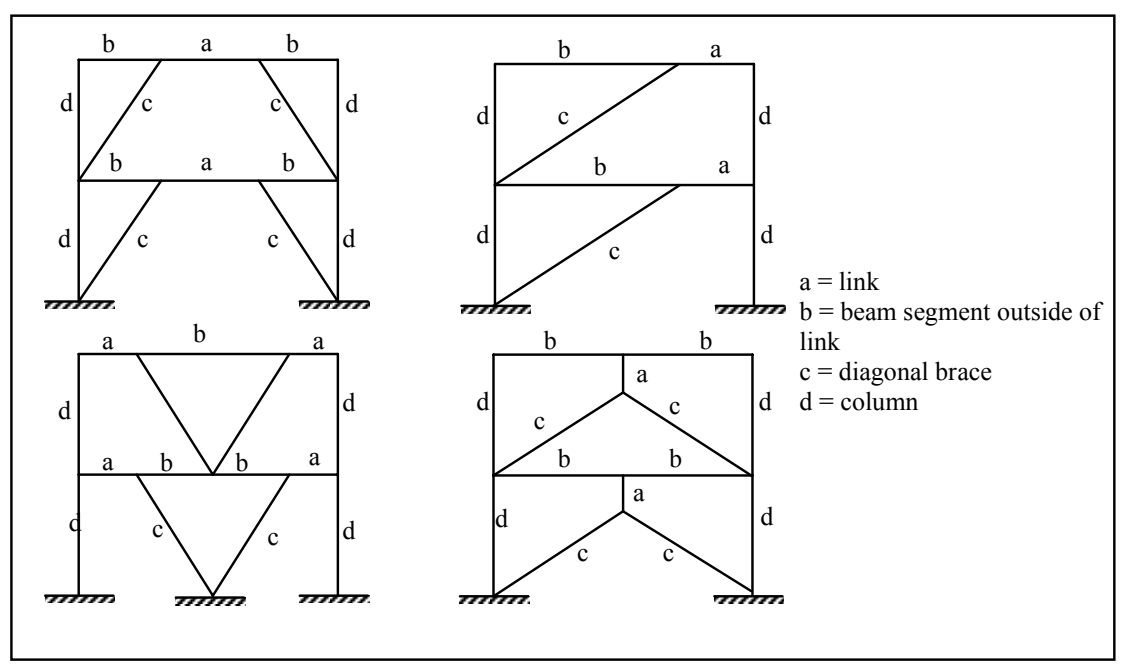

Figure 2 Eccentrically Braced Frame Configurations [3].

\subsection{Link Element Characteristic in EBF System}

Link is an element inside EBF system which behaves as a short (deep) beam and on both sides apply shear forces with opposite directions along with the corresponding flexures (see Figure 3).

Plastification occurring on link element is caused by both forces above; therefore link element behavior in overall can be classified into two types namely; 1) Moment (flexural) link and 2) Shear link. Link is classified as shear link if yielding is caused primarily by shear, and is classified as moment link if the yielding is caused by flexural moment.

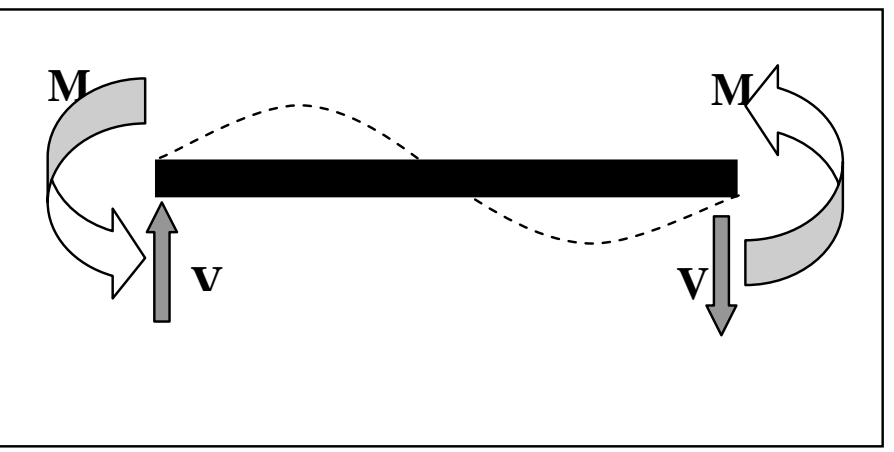

Figure 3 Shear Forces on Link Element [4-5]. 
Deformation after yielding occurred of a link beam is caused by either shear yielding or flexural yielding or combination of both. By applying a simple analytical model, it can be determined the exact limit between flexural and shear mechanisms. This limit can be described by using a shear span which simultaneously yields in both flexure and shear condition [6].

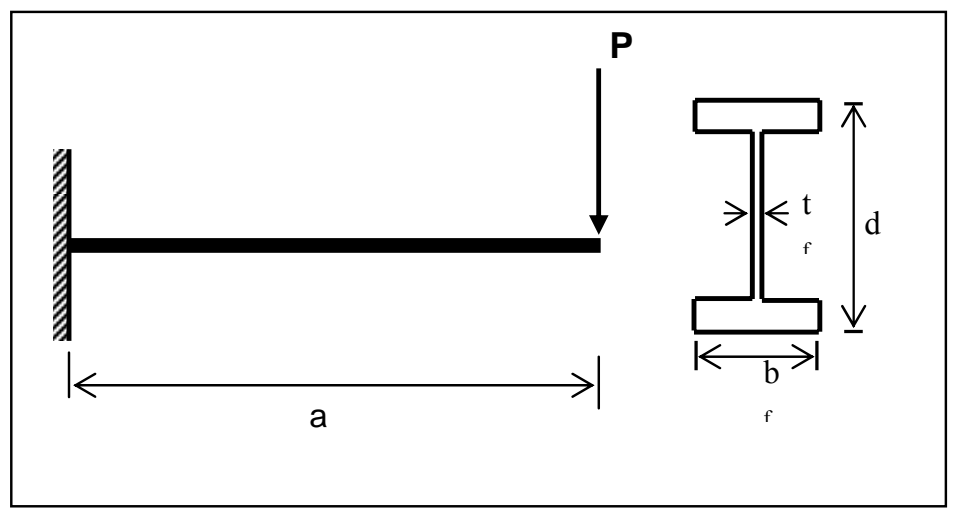

Figure 4 Shear Span and Surface of A Simple Cantilever Beam [7-8].

Shear span is a comparison between moment with shear on a point or spacing between point $\mathrm{M}=0$ (inflection point) with a maximum moment point with no increase in load between both points. Shear span in its simplest form is described as a cantilever beam loaded on its end, as seen in Figure 4. Behavior of link in EBF system during mechanism situation is described with the same concept, which is a simple shear span as in Figure 4. A balance strength ratio is achieved when shear span experiences both flexural and shear yielding simultaneously.

$$
a=\frac{M}{V}
$$

Where $\mathrm{a}=$ length of cantilever beam shear span, $\mathrm{M}=$ moment working on beam, $\mathrm{V}=$ shear force working on beam. Meanwhile length of cantilever in balanced plastic condition can be translated in the formula:

$$
a_{b}=\frac{M_{p}}{V_{p}}
$$

where: $M_{p}=Z_{x} \cdot F_{y}, \quad V_{p}=0,6 \cdot F_{y} \cdot d \cdot t_{w}$

$$
a_{b}=\text { Comparison of balance strength ratio }
$$


$\mathrm{Mp}=$ plastic moment, $\mathrm{Vp}=$ plastic shear force, $\mathrm{Zx}=$ surface modulus $\mathrm{x}$ axis direction, $d=$ height of beam surface profile $\mathrm{WF}, \mathrm{t}_{\mathrm{w}}=$ thickness of web profile $\mathrm{WF}, \mathrm{Fy}=$ yield stress.

The cantilever beam will yield caused by shear if the cantilever's length is less than $a_{b}$ and will yield caused by flexure if the length of cantilever exceeds $a_{b}$. From the perspective criteria, link design is considered as a confined beam on both ends, balanced link length can be given in the formula:

$$
e_{b}=2 a_{b}=2 \frac{M_{p}}{V_{p}}
$$

where: $\mathrm{e}_{\mathrm{b}}=$ balance link length .

Based on the yield mechanism occurring in link beams, link is divided into two namely moment link and shear links depending on flexural and shear yields mechanism. However, there is no apparent limit between shear link and moment link. To identify a link yields caused by moment or shear, experiments are required.

Pure shear occur during link length (e) maximum $80 \%$ from shear span length in equilibrium $\left(\mathrm{e}_{\mathrm{b}}\right)$; thus $\mathrm{e} \leq 80 \% \mathrm{e}_{\mathrm{b}}=0,8.2 \mathrm{ab}=1,6 \mathrm{Mp} / \mathrm{Vp}$. While pure flexural condition is considered to occur when "e" exceeds $5 \mathrm{Mp} / \mathrm{Vp}$

Behavior of beam link between both conditions is illustrated by applying strength ratio $\mathrm{Mp} / \mathrm{Vp}$ as follows: 1) pure shear link if: e $<1,6 \mathrm{Mp} / \mathrm{Vp}, 2$ ) dominant shear link if $1,6 \mathrm{Mp} / \mathrm{Vp}<\mathrm{e}<2,6 \mathrm{Mp} / \mathrm{Vp}, 3)$ flexural dominated link if: $2,6 \mathrm{Mp} / \mathrm{Vp}<\mathrm{e}<5,0 \mathrm{Mp} / \mathrm{Vp}, 4)$ pure flexural link if: e $>5 \mathrm{Mp} / \mathrm{Vp}$.

\subsection{Effects of Web Stiffener towards Shear Link Performance}

Due to the high ductility demand on short links, the flange area of the link surface (WF profile) might experience buckling phenomena; therefore it is required to install web stiffeners. If these web stiffeners are not installed, a large premature torsional buckling may occur on the web which in turn might cause lateral torsional buckling on the link. Figure 6 shows shear link WF profile with a spacing to web stiffener as far as "a" where " $a$ " is web stiffener spacing. Experiments conducted by Ghobarah [9] on short links has shown links with web stiffeners result in bigger shear ability, along with wider and more stabile hysteric loops. Other researchers such as Kasai and Popov [10,12] have determined a few simple requirements regarding web stiffener spacing with a maximum inelastic rotational angle $\left(\gamma_{\mathrm{p}}\right)$ to the beginning of web torsional buckling, which are as follows : 


$$
\begin{array}{lll}
\mathrm{a}=29 \mathrm{t}_{\mathrm{w}}-\mathrm{d} / 5 & \text { then } & \gamma_{\mathrm{p}}= \pm 0.09 \mathrm{rad} . \\
\mathrm{a}=38 \mathrm{t}_{\mathrm{w}}-\mathrm{d} / 5 & \text { then } & \gamma_{\mathrm{p}}= \pm 0.06 \mathrm{rad} \\
\mathrm{a}=29 \mathrm{t}_{\mathrm{w}}-\mathrm{d} / 5 & \text { then } & \gamma_{\mathrm{p}}= \pm 0.03 \mathrm{rad} .
\end{array}
$$

$a=$ web stiffener spacing, $d=$ beam height, $t_{w}=$ web thickness.

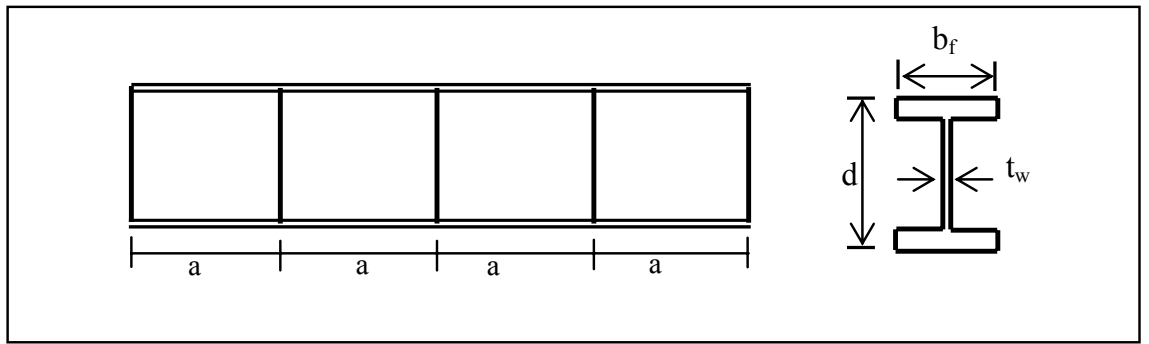

Figure 5 Shear Link with Spacing of Intermediate Web stiffener "a" [11].

The current code of practice of web stiffener spacing is listed in AISC 2005, intermediate web stiffener for shear links cannot be less than $\left(30 t_{w}-d / 5\right)$ and the thickness of web stiffener cannot be less than $t_{w}$ or $10 \mathrm{~mm}$.

\section{$4 \quad$ Method of Research}

This research was conducted with two methods, namely, (1) numerical study and (2) experimental study. Numerical study is aimed to examine behavior of shear link under cyclic and monotonic load, also to determine parameters which influence significantly under the performance of shear link. Numerical study was conducted with non linear finite element using MSC/NASTRAN software where link is modeled using element of Shell CQUAD4. Element models, up until shear links WF profile were made. These were fixed on both ends, where one end was given 1 DOF in direction of the $Z$ axis, which can be seen in Figure 6. The load given to test specimen was in the form of static monotonic and cyclic load under displacement control.

Parameters analyzed in this numerical study were: flange thickness, web thickness, web stiffener thickness, spacing of web stiffener, also thickness and geometric model of diagonal web stiffener. Next an experimental study was conducted to perform a validation towards results of numerical study. 


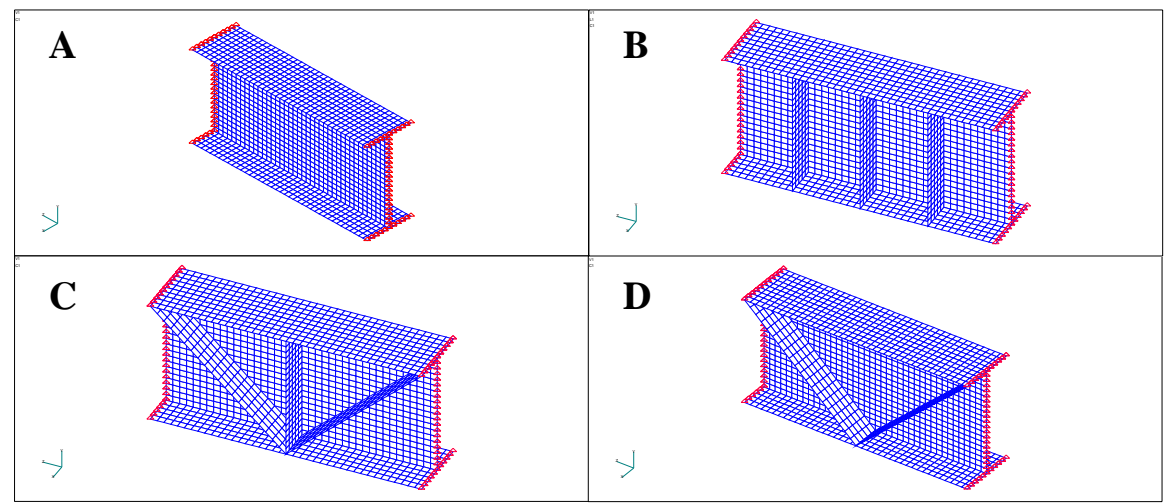

Figure 6 Finite element model of shear link with various type of stiffner $[4,5,7,8]$.

Experimental study was conducted in Structural Mechanic Laboratory Center for Industrial Engineering ITB. In this study, three test specimens were created in the form of shear link with and without diagonal web stiffeners. Shape and dimension of the three test specimens were adjusted with element models until ones analyzed in numerical study. The test specimens was created from profile WF 200.100.5,5.8 (as in numerical study profile), the thickness of web stiffener was $10 \mathrm{~mm}$, while the thickness of diagonal web stiffener were made in two variations, $8 \mathrm{~mm}$ and $4 \mathrm{~mm}$ as seen in Figure 7 .

After creating test specimens, loading frames and the software were then prepared along with tools to perform testing. Each test specimen is placed on support of test specimen and connected to the actuator with joint plates $40 \mathrm{~mm}$ thick, connection of joint plates to actuator is using $27 \mathrm{~mm}$ bolts. 


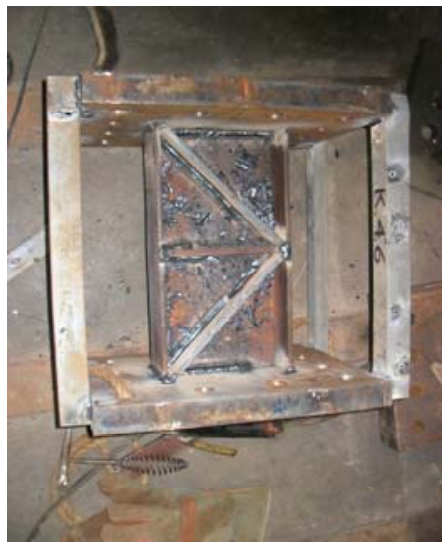

(a)

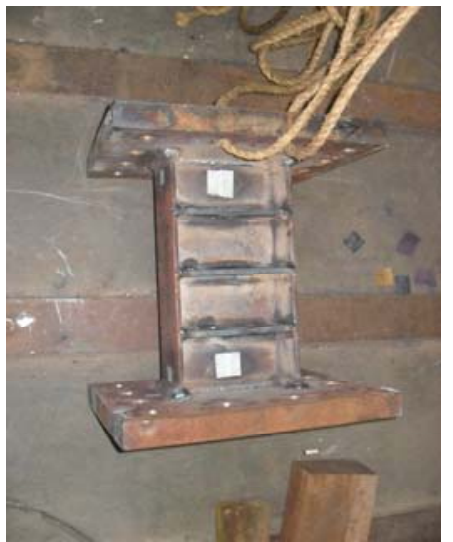

(b)

Figure 7 The form of specimens of shear link with and without diagonal web stiffener.

Loading pattern given on test specimens is based on load patterns in AISC 2005. Applied load are cyclic loads with displacement control. Figure 9 shows a graph of load pattern applied on the test specimen.

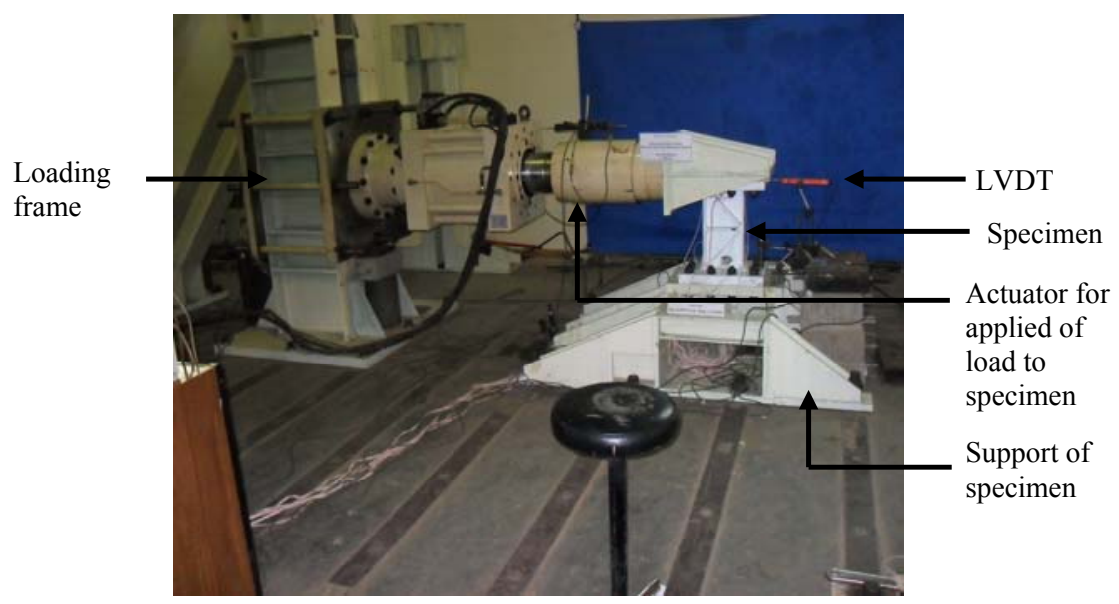

Figure 8 Set up of equipment and specimen of shear link. 


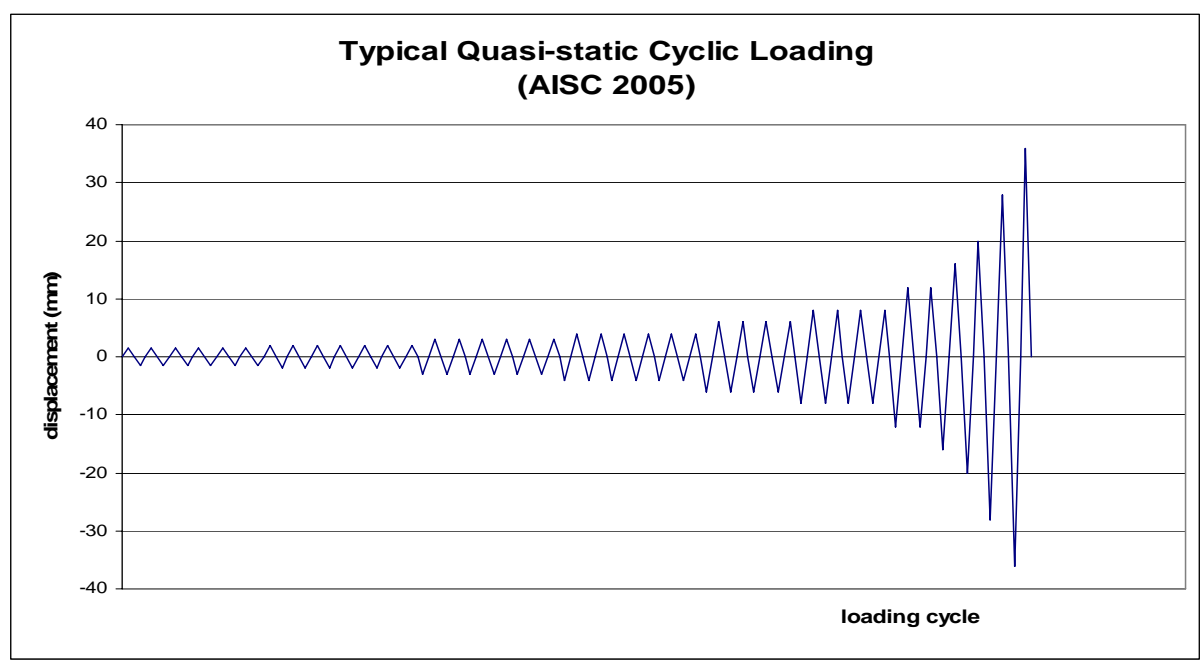

Figure 9 Quasi-static cyclic loading pattern were subjected to the specimens according with AISC 2005.

\section{$5 \quad$ Numeric Study Results}

Results of numerical study have shown parameters which significantly affect the performance of shear link. These parameters are: thickness of diagonal stiffener and the geometric model of the stiffener. A few parameters such as spacing and thickness of web stiffener, has no significant effect on link performance. Other parameters, such as thickness of flange and thickness of web, is kept constant in this analysis because these parameters cannot be modified in the field due to the applied WF profile which is default from the factory. Therefore this research analysis topic is focused on diagonal stiffener and vertical stiffener where those parameters could be modified easily to increase performance of shear link.

\subsection{Effect of Web stiffener on Shear Link Performance}

AISC 2005 regulated intermediate web stiffener spacing for shear link to not be less than $\left(30 t_{w}-d / 5\right)$ and the thickness to not be less than $t_{w}$ or $10 \mathrm{~mm}$. This research applies a spacing of stiffener to be $100 \mathrm{~mm}$ and thickness of stiffener $10 \mathrm{~mm}$. To examine effect of spacing and thickness to the performance of shear link, observation of three stiffener's spacing variation as much as $200 \mathrm{~mm}(2$ spacings); $133.3 \mathrm{~mm}$ (3 spacing's) and $100 \mathrm{~mm}$ (4 spacing's) was conducted. Thickness of stiffener was done in three variations: $4 \mathrm{~mm}, 6 \mathrm{~mm}$, and $10 \mathrm{~mm}$. 


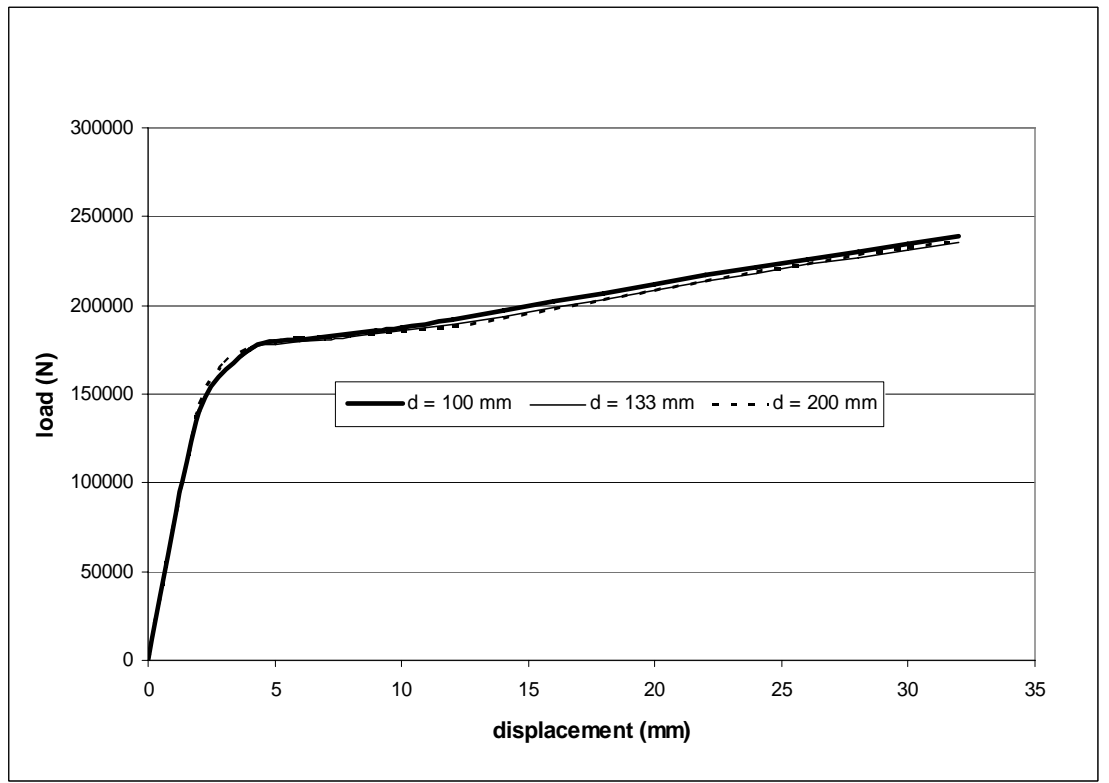

Figure 10 Link Performance with difference vertical web stiffener spacing.

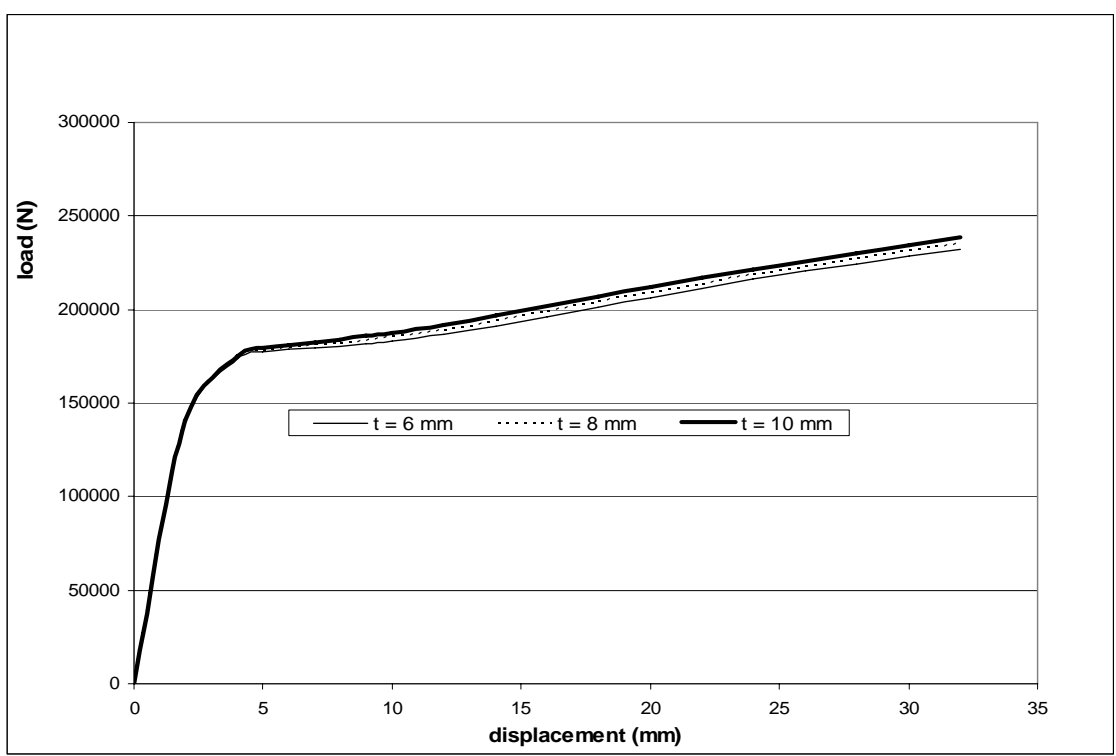

Figure 11 Link Performance with difference vertical web stiffener thickness. 
Results of non linear finite element analysis are presented in the form of load vs. displacement curves. Load vs. displacement curve in Figure 10 shows effects of web stiffener spacing on performance of shear link. The nonlinear analysis shows that the spacing of stiffener does not have a significant effect, due to the vertical stiffener attached on IWF web profile which only delays local buckling occurring on the web. Generally encountered IWF profile in the market has a compact surface characteristic resulting in minimizing the effect of local buckling occurring on the section. The same applies to stiffener spacing; variation of stiffener thickness also does not have a significant effect on the performance of shear link. Plot on Figure 11 illustrates the effect of stiffener thickness on the performance of shear link.

\subsection{Increase of Shear Link Performance through Installation on Diagonal Stiffener}

Based on the previous analysis, there is no significant effect on the variety of stiffener thickness and spacing of web stiffener to the performance of shear link, although regulations regarding stiffener thickness and spacing of web stiffener have been regulated in AISC 2005 [3] and from previous researches.

Table 1 Models of Shear Links for Cyclic Analysis.

\begin{tabular}{|c|c|c|c|}
\hline Model & Sketch & $\begin{array}{l}\text { The thickness of } \\
\text { Vertical Plate } \\
\text { (mm) }\end{array}$ & $\begin{array}{c}\text { The thickness } \\
\text { of Diagonal } \\
\text { Plate } \\
\text { (mm) }\end{array}$ \\
\hline $\begin{array}{c}\text { DV8 } \\
\text { (spec.I) }\end{array}$ & & 10 & 8.0 \\
\hline $\begin{array}{c}\text { WS3 } \\
\text { (spec.II) }\end{array}$ & & 10 & \\
\hline $\begin{array}{c}\text { DV42 } \\
\text { (spec.III) }\end{array}$ & & 10 & 4.2 \\
\hline
\end{tabular}

In this analysis, an innovation to increase performance of shear link through the installation of diagonal web stiffener on web area was attempted. The hypothesis the research is by installing a diagonal stiffener, a change in surface properties may occur. These changes include increase of inertia moment and 
shear surface. The installation is also predicted to prevent local buckling on link element. Although there is yet a code or previous research results which regulate the design of diagonal stiffener on link, numerical and experimental studies to further determine shear link behavior with diagonal stiffener on the web area was conducted. Table 1 shows a sketch model of the analyzed specimens with cyclic loading.

Based on the results of initial studies which have been performed numerically, it was found an indication that the installation of diagonal bracing on the web profile of WF on the link element can increase link capacity of lateral force resistance, and improve the ability of shear link in the energy dissipation. Indicators ability shear links in the energy dissipation is expressed in the form of hysteretic curve Force vs. Displacement relationship obtained from the quasistatic loading (cyclic) as shown in Figure 12.

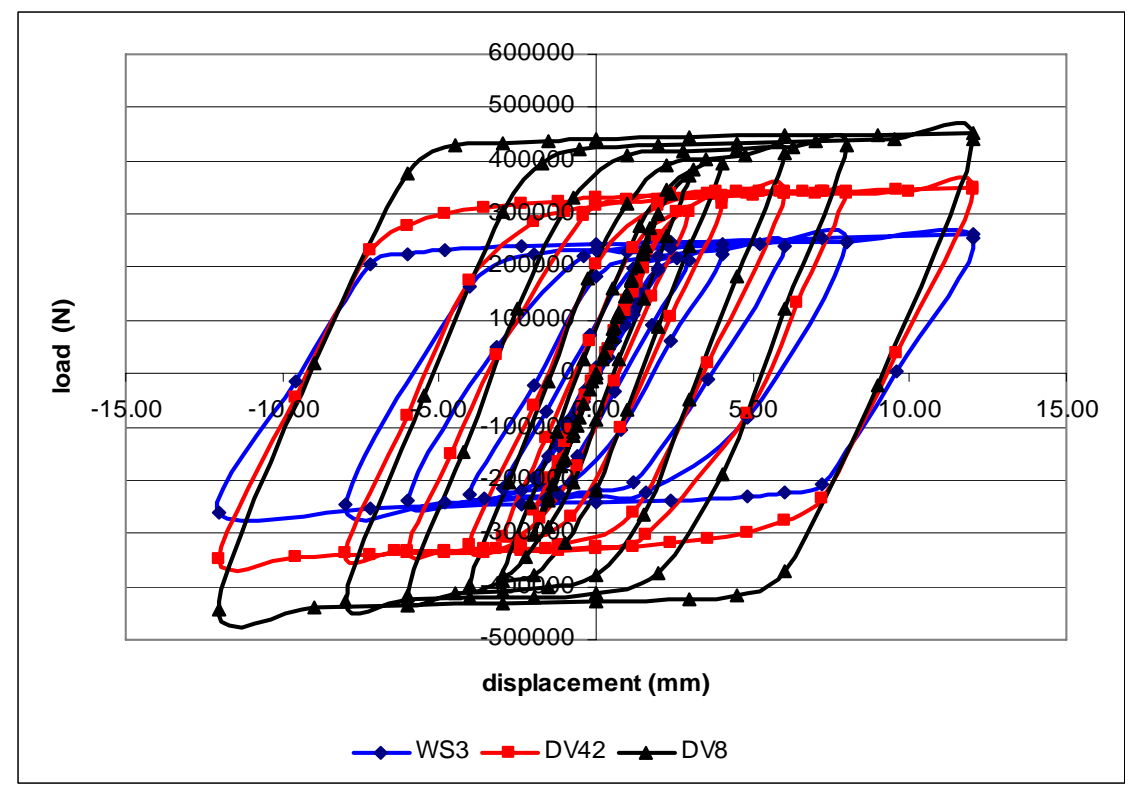

Figure 12 Comparison of shear link hysteretic curve with thickness variation of diagonal bracing and shear link under AISC-2005 standards.

\section{Experimental Study Results}

Experimental tests conducted on three specimens of each link namely link without diagonal stiffener, diagonal stiffener link with $4.2 \mathrm{~mm}$ thick and a link 
with a diagonal stiffener of $8 \mathrm{~mm}$. All specimens were steel profile of WF 200.100.5, 5.8 and $400 \mathrm{~mm}$ in length.

The first specimen (Specimen I) is capable to withstand large lateral force at failure. This is because the influence of the diagonal stiffener increasing the stiffness and the strength of the specimens. However, thicker diagonal stiffener can inhibit plastification of the web leading to brittle failure mechanism. The amount of the maximum load that can be resisted for specimen 1 is $517.222 \mathrm{~N}$ in compression and $403.466 \mathrm{~N}$ in tension whilst the value of the corresponding maximum displacement of the specimen is $11.76 \mathrm{~mm}$ in tension and $10.94 \mathrm{~mm}$ in compression.

Specimen II is the standard shear link complying with the AISC 2005 is capable to withstand the lateral force of $353.755 \mathrm{~N}$ in compression and $310.409 \mathrm{~N}$ in tension, whilst the value of the corresponding maximum displacement of specimens is $24.68 \mathrm{~mm}$ in compression and $25.38 \mathrm{~mm}$ in tension. The failure mechanism, however, is more ductile compared to the first Specimen.

Specimen III is a shear link with diagonal stiffener of $4.2 \mathrm{~mm}$ thick, underwent plastification on the flange, web and diagonal stiffener before collapse. Because the thicknesses of the diagonal stiffeners are relatively thin with lower yield stress, buckling has occurred in the diagonal stiffener before the collapse of the specimen. Maximum load that can be retained by the specimen is $446.992 \mathrm{~N}$ in compression and $326.323 \mathrm{~N}$ in tension, whilst the corresponding maximum displacement is $16.58 \mathrm{~mm}$ in compression and $18.04 \mathrm{~mm}$ in tension. The failure mechanism is close to Specimen with comparable ductility.

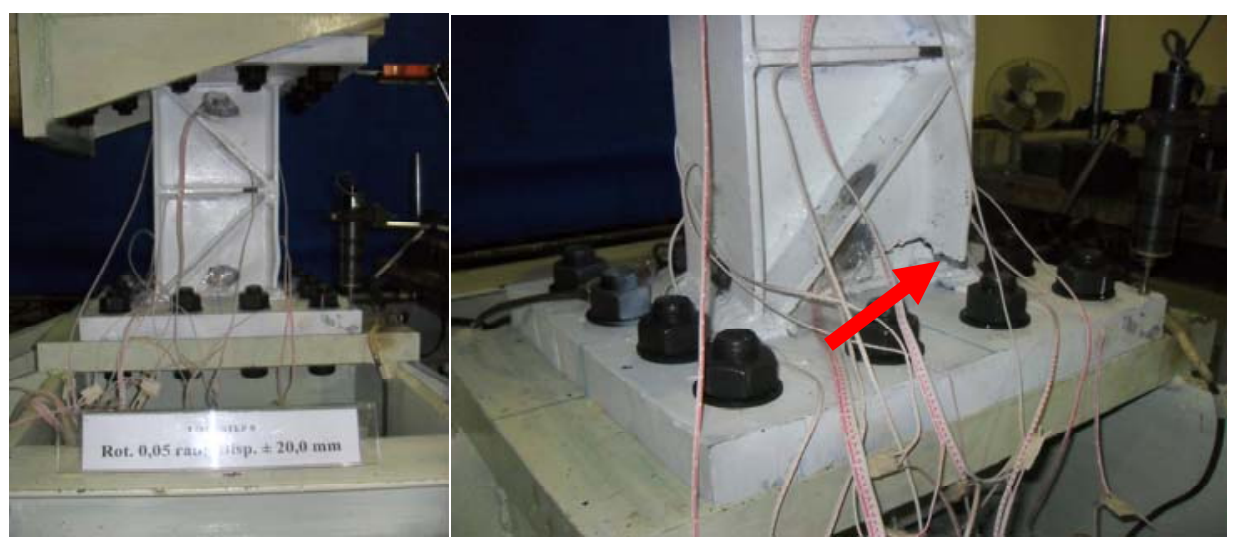

Figure 13 Cracks in the flange of the Specimen I in the top of the welded joints, no buckling occurred in the diagonal stiffener during collapse. 
All of the specimens have the same failure modes starting with the occurrence of cracks on the flange around the joint at the supported area. High stresses concentration due to thick welded joints in these positions causes the vicinity becomes brittle and it is prone to crack or fracture. This phenomenon accelerates the collapse of the specimen and the cracking (fracture) of the specimen. However, this behavior is difficult to model in numerical studies. Figures 13 to 15 show cracks that occurred in the third Specimen at failure.

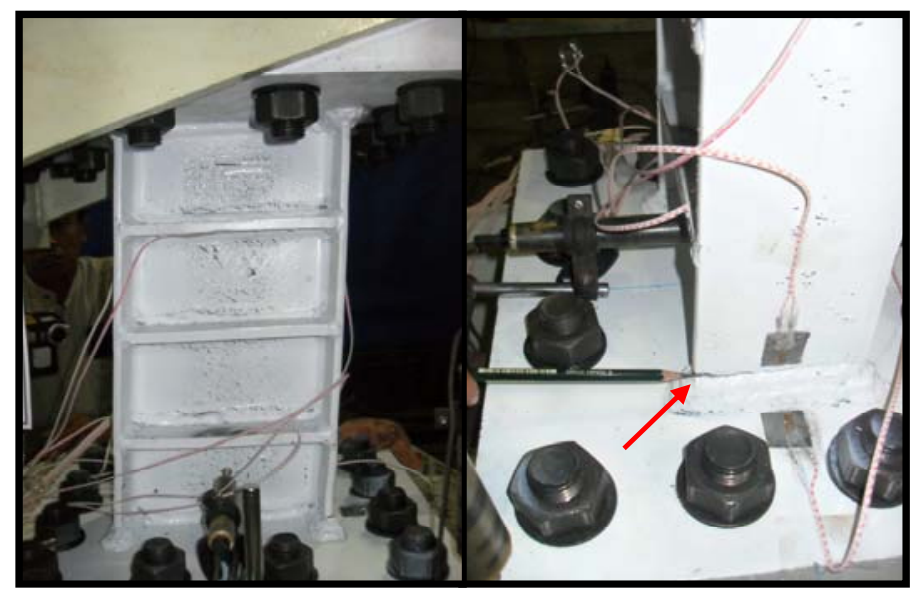

Figure 14 Fracture in the flange of the Specimen II at the top of the welded joints at the time of collapse.

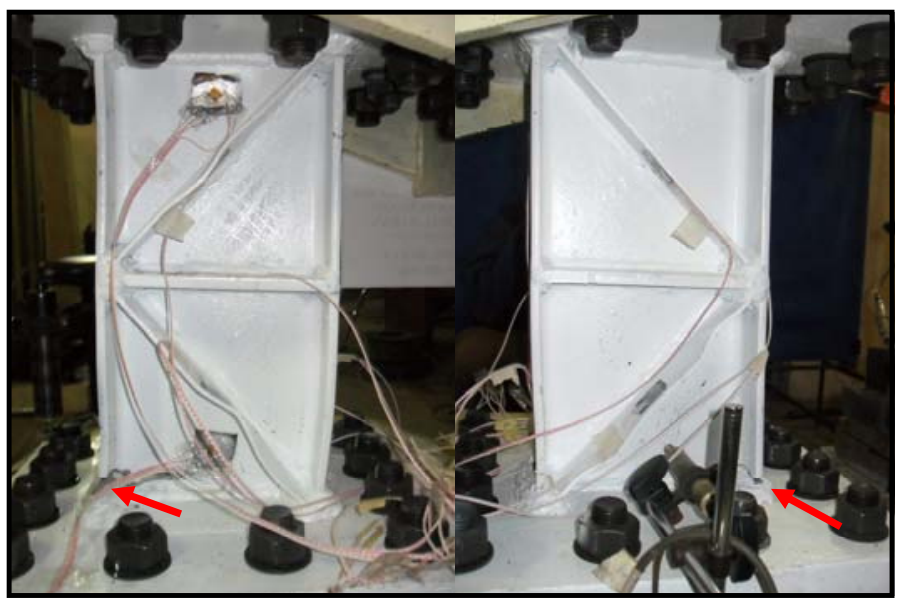

Figure 15 Fracture in the flange on the third specimen in the top of the welded joints at the time of the collapse. 


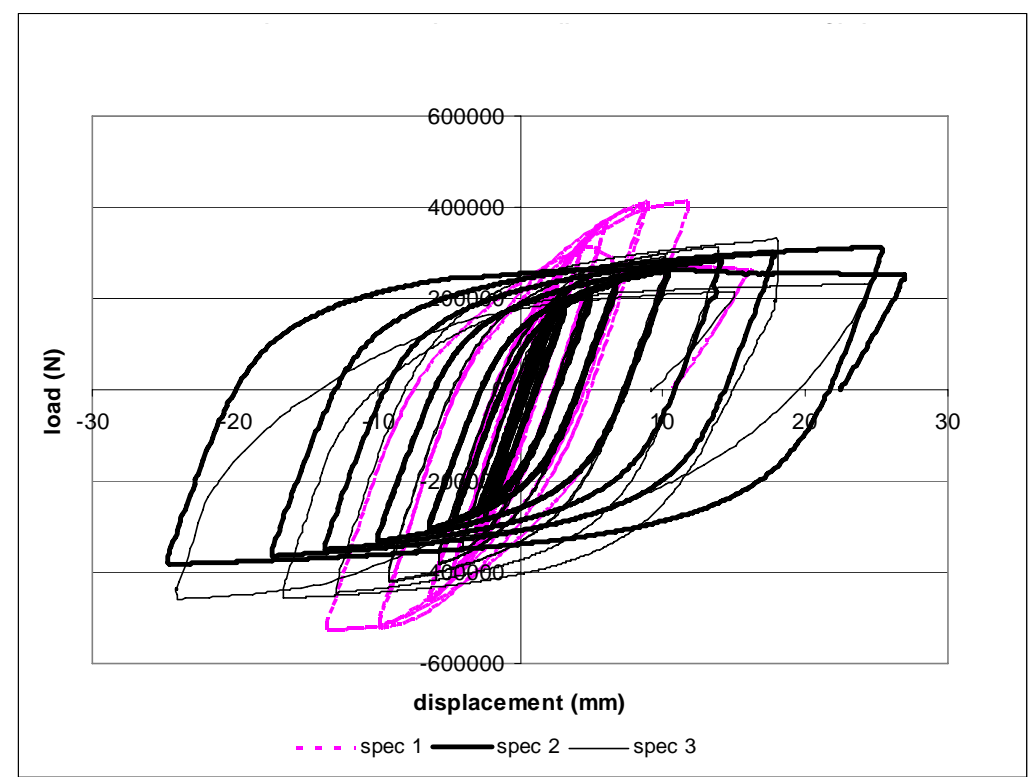

Figure 16 Hysteretic curves of three specimens.

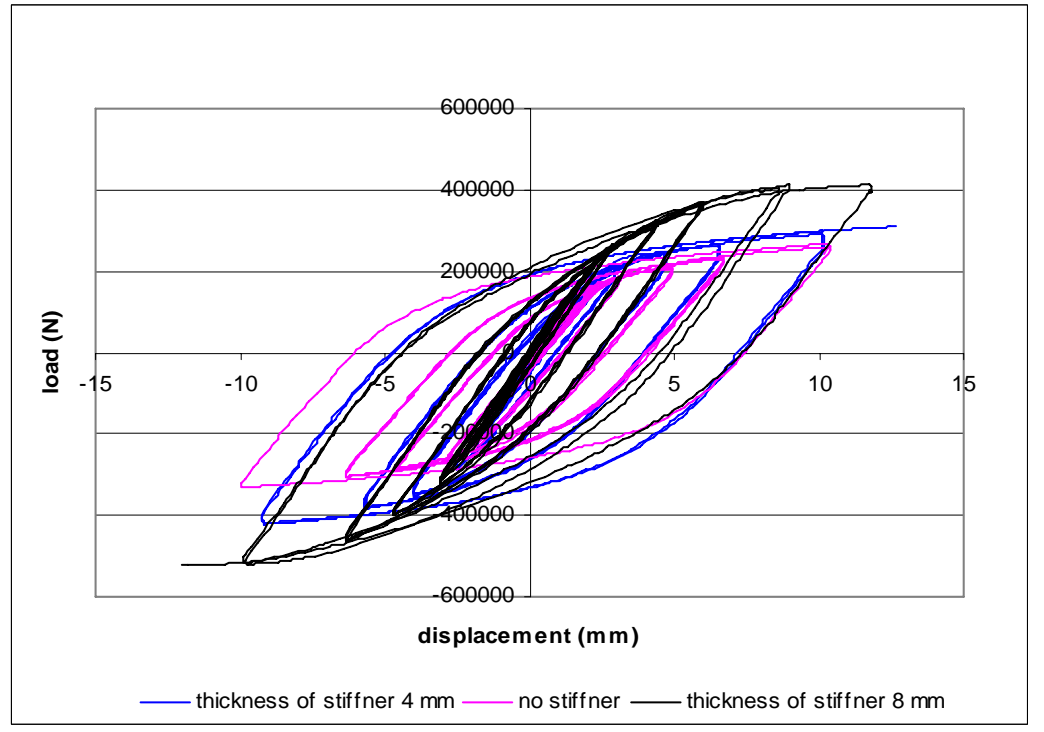

Figure 17 Response of specimens under stable condition (rotation of 0.03 radiant). 
The comparisons among the hysteretic curves of Specimens are showed in Figure 16. The curves show that the link with the diagonal stiffener has the ability to withstand greater lateral force, but less inelastic deformation. To achieve the ability to the link with optimal performance, the thickness and material properties of diagonal stiffener must be design in such a way as to not impede the plasticity process of the web. The Figure also shows that the shear link with a thinner thickness of the stiffener has fatter hysteretic curve indicating a better performance despite the lateral force is slightly lower.

Hysteretic curves in Figure 16 cannot be used directly to compare the performance of individual specimens because failure occurs at different load. In order to compare the performance of the samples individually stable condition should be chosen rather than at failure. Stable condition in this case is defined as a condition whereby the three specimens were already experiencing inelastic deformation without collapse of any parts of the specimens or stable inelastic condition. In this test a stable inelastic condition occurs when the rotation is 0.03 radians or displacement of $12.00 \mathrm{~mm}$ as shown in Figure 17.

\section{$7 \quad$ Cyclic Analysis towards Performance of Shear Link Specimens}

Cyclic analyses of the three specimens were conducted to compare the shear link performance of the three specimens for strength, stiffness, energy dissipation, and ductility based on the results of both experimental work and numerical model.

Strength is defined as the maximum lateral force (shear force) that can be retained by the specimens in each stage of loading (load step). Load vs. displacement curve in Figures 18 and 19 show the comparison of the strength of three specimens from the results of experimental tests and numerical studies. Load vs. displacement curves in the figure shows that Specimen I (shear link with diagonal bracing of $8 \mathrm{~mm}$ thick) obtained the highest strength in a lateral withstanding tension and compression compared to Specimens II and III.

Stiffness is defined as secant stiffness is the ratio between the maximum lateral force and displacement at each stage of loading (load step). Similar to the analysis of strength, the secant stiffness for the three models of the specimens were observed in the tension and compression. Figure 20 shows the relationship between the stiffness vs. displacement of the experimental tests. Specimen I has the highest secant stiffness, despite it is more brittle compared to Specimens II and III. In numerical studies, the earlier failure phenomenon cannot be picked up modeled with computer software used. The results of numerical studies 
shown in Figure 21 are in a good agreement with the experimental work that the use of the diagonal stiffener improves the stiffness of the shear link.

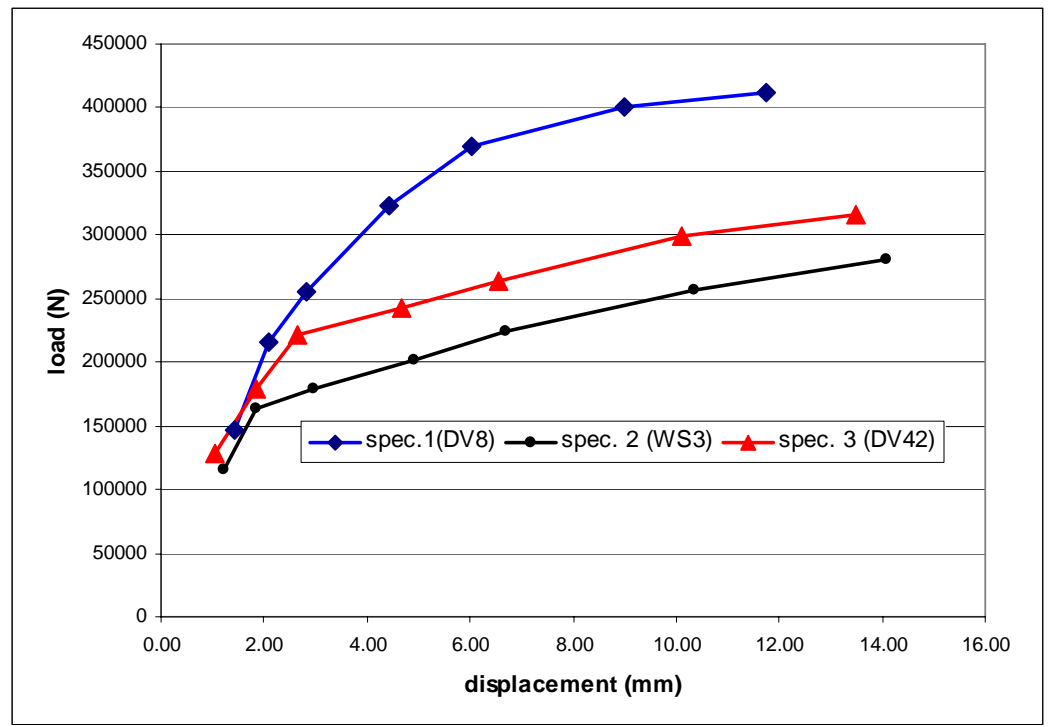

(a)

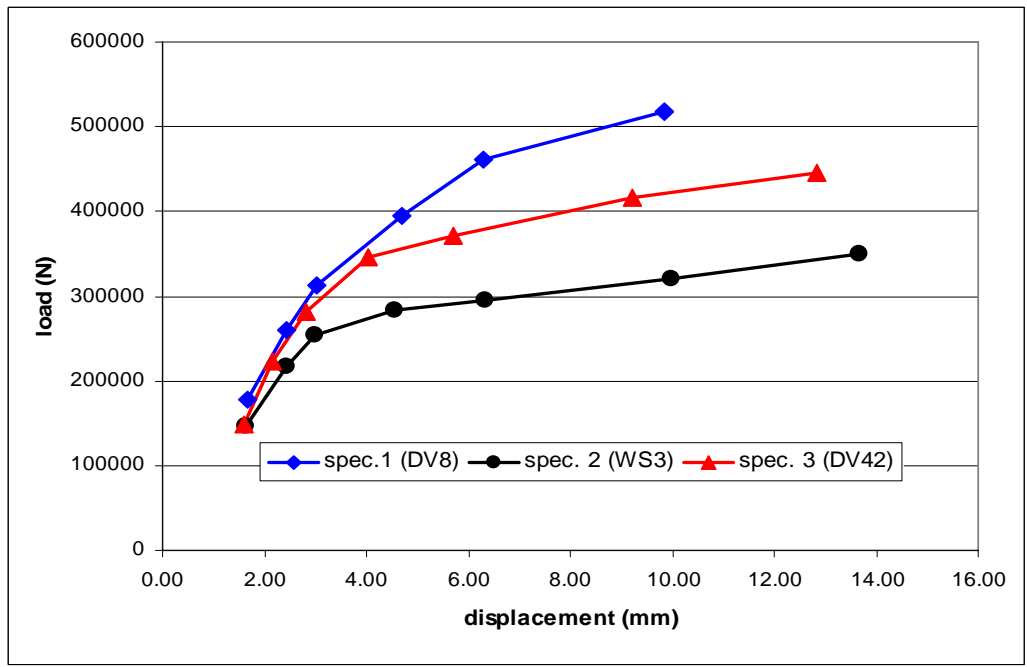

(b)

Figure 18 Comparison of shear strength of three model specimens of shear link, the experimental results in tension (a) and the compression (b). 


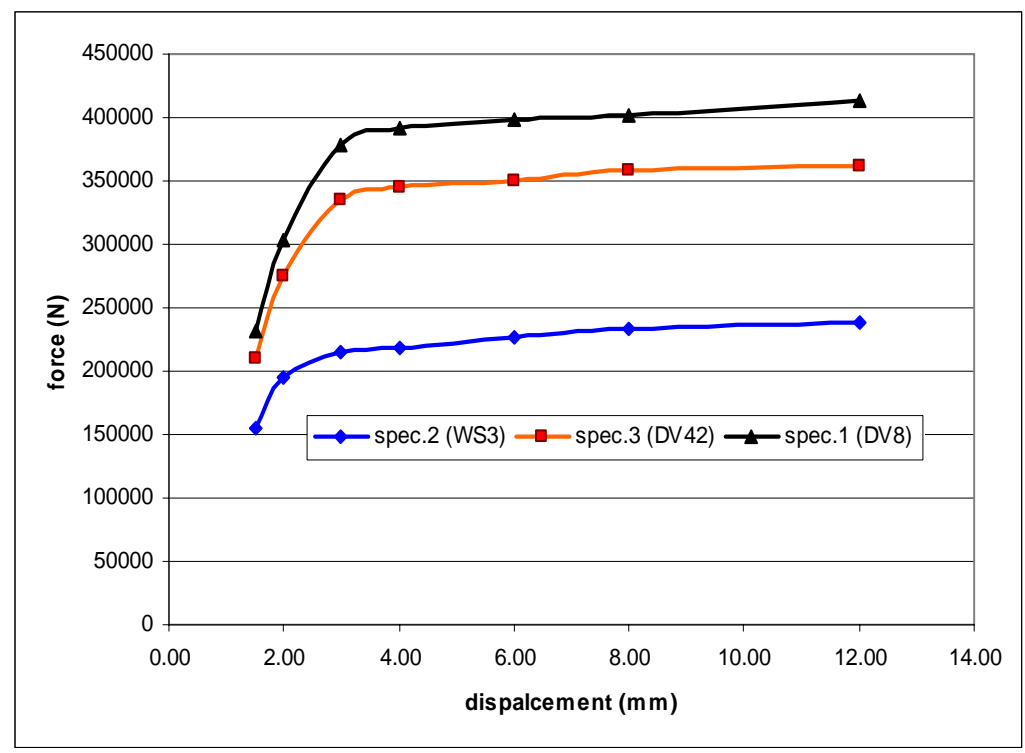

(a)

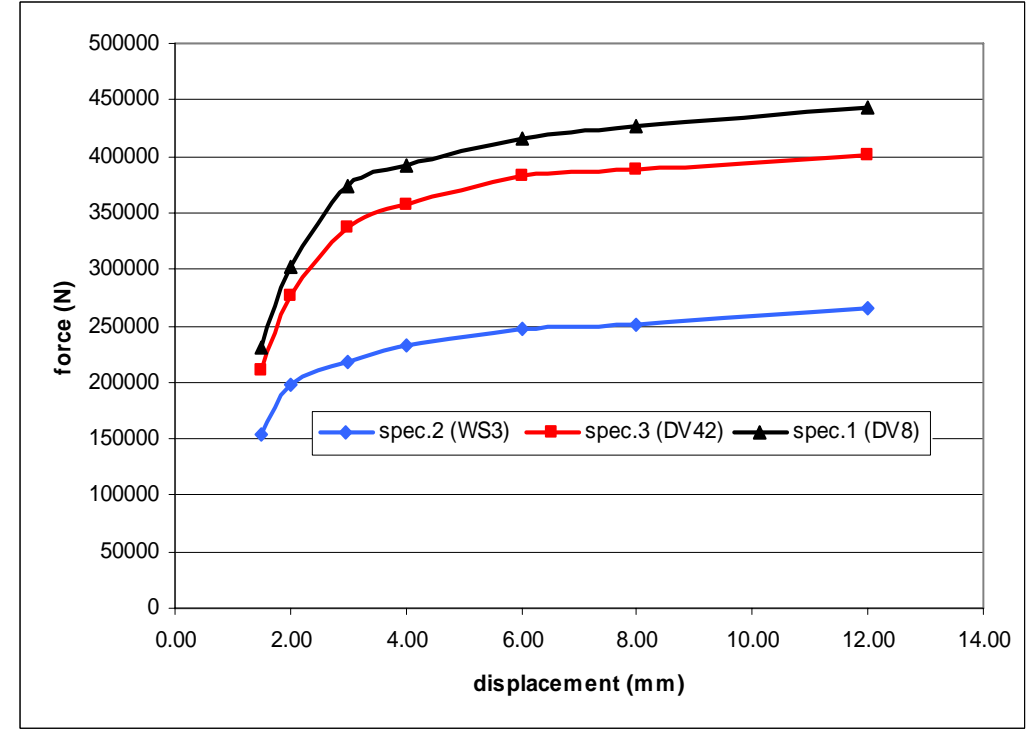

(b)

Figure 19 Comparison of shear strength of three model specimens of shear link, the results of numerical studies on the condition of tension (a) and the compression (b). 


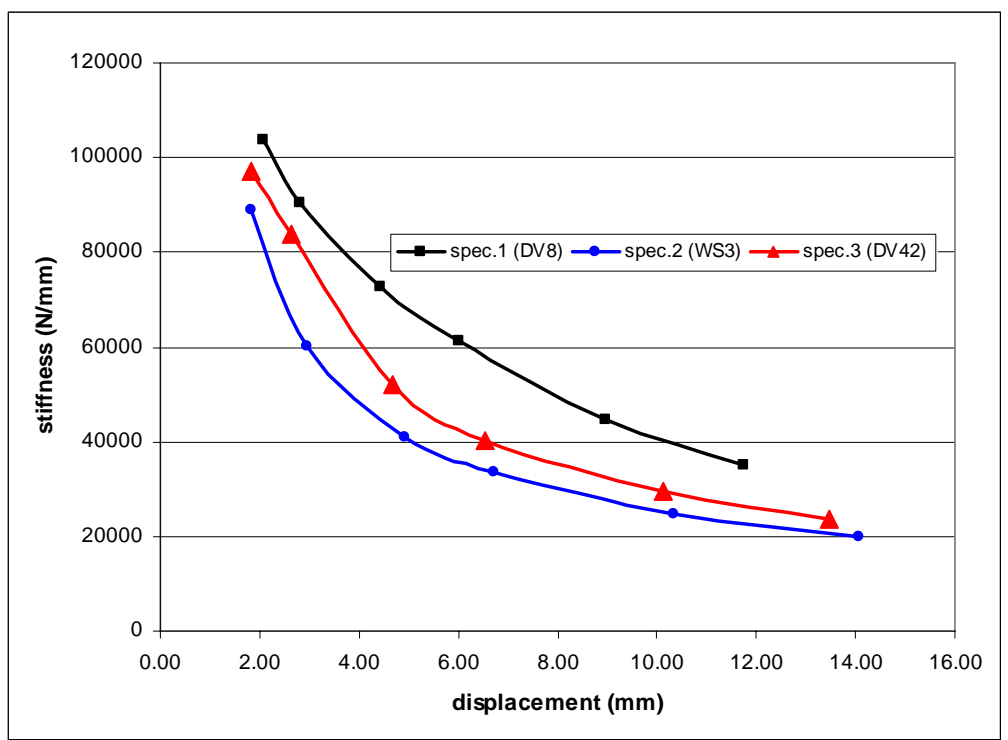

(a)

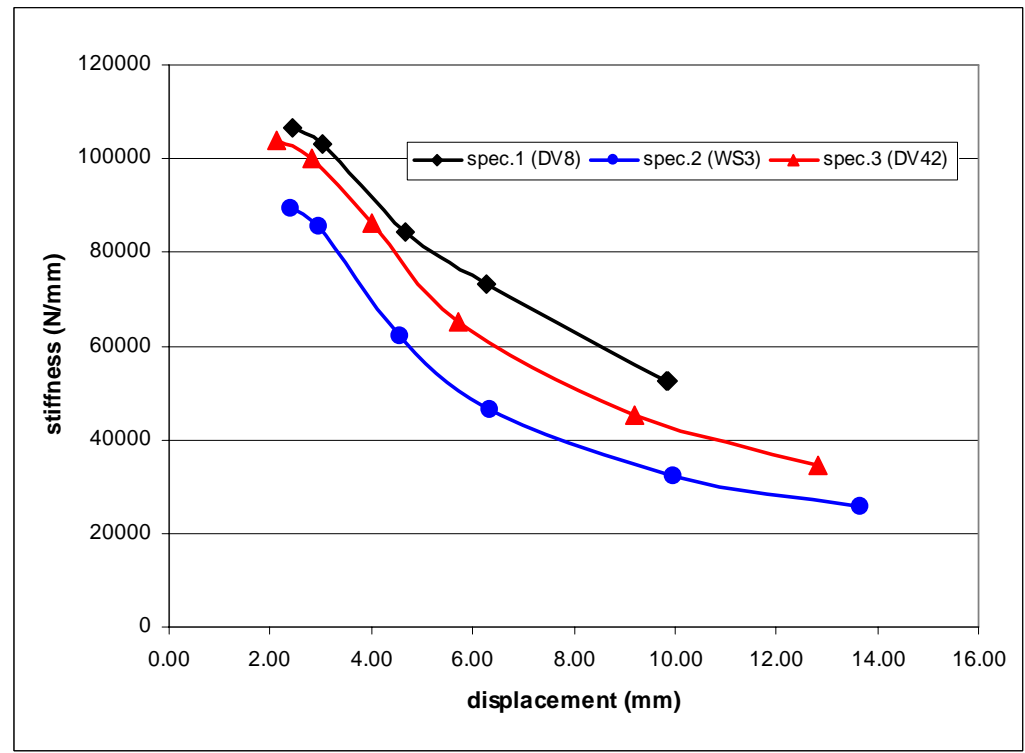

(b)

Figure 20 Comparison of secant stiffness of the specimens of experimental work in tension (a) and compression (b). 


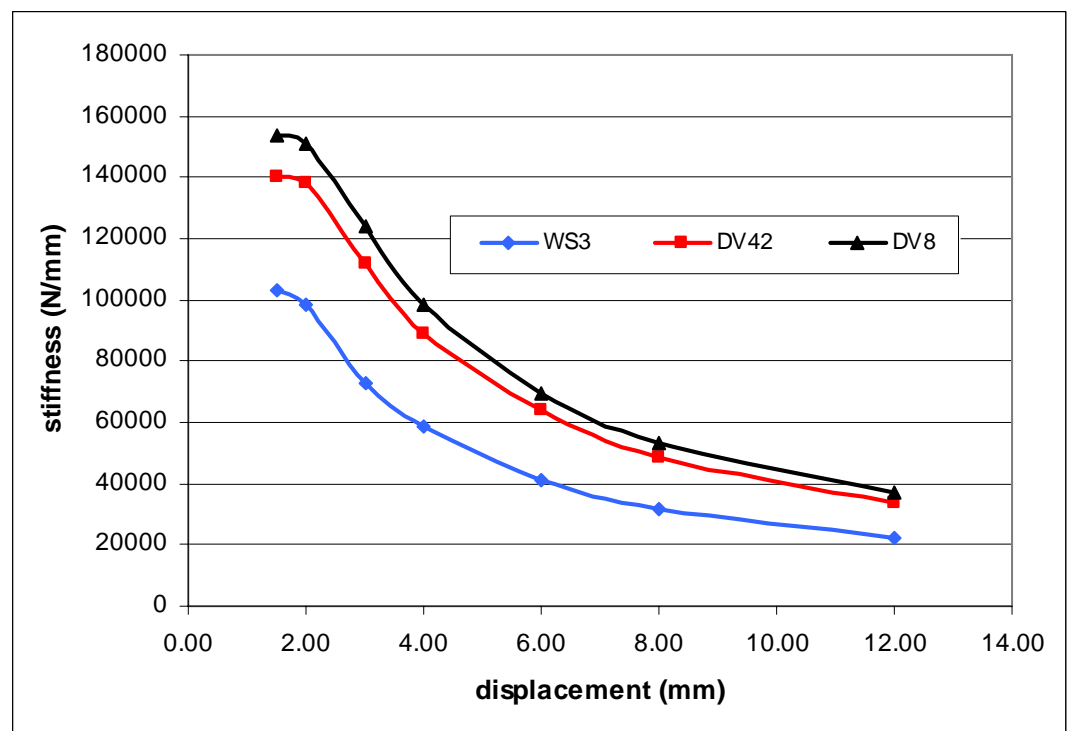

(a)

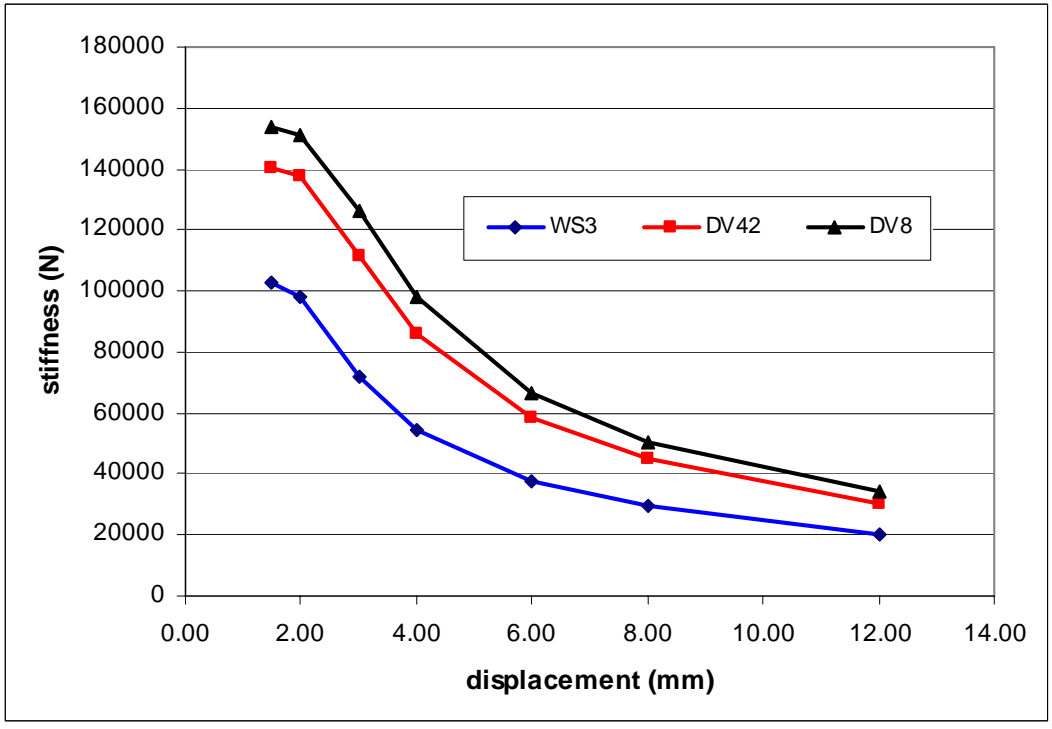

(b)

Figure 21 Comparison of secant stiffness of three numerical model of specimens in tension (a) and compression (b). 


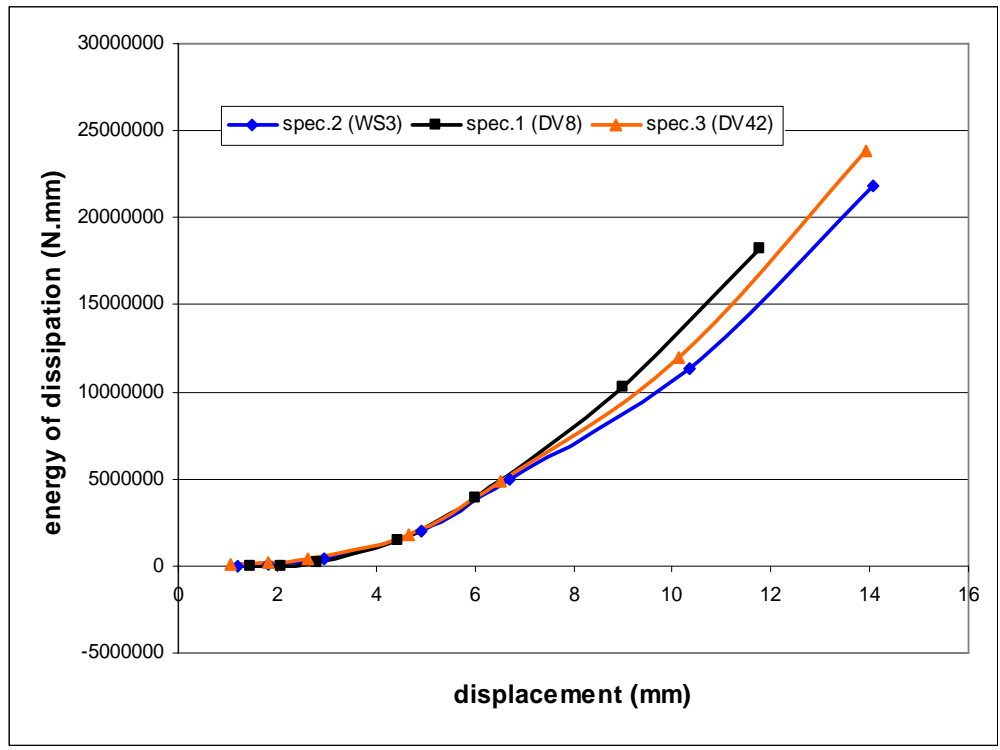

(a)

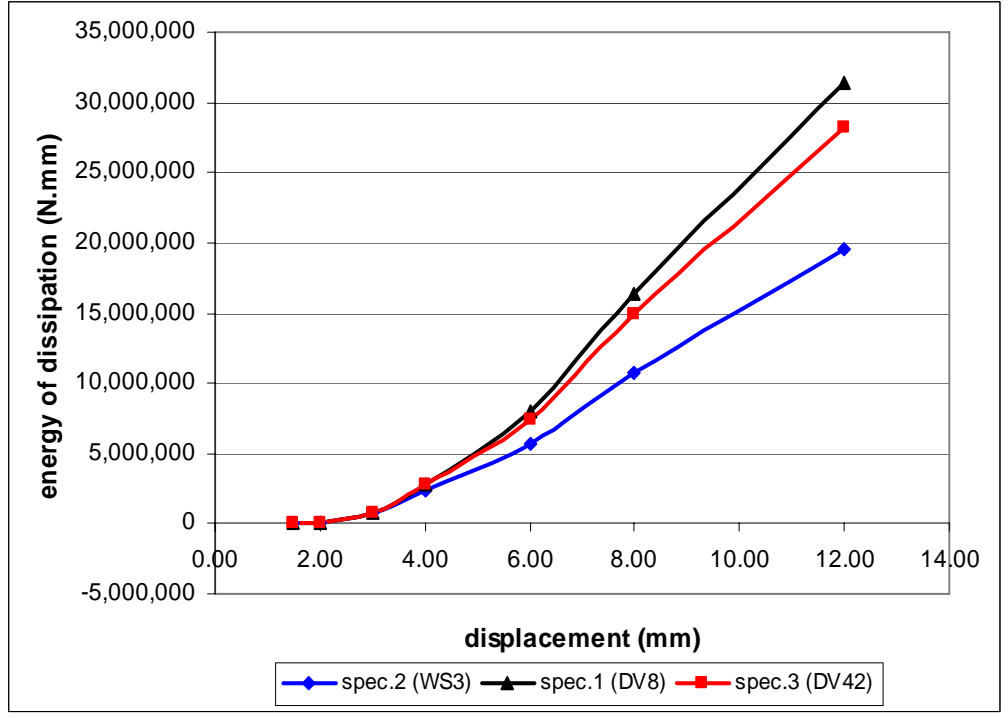

(b)

Figure 22 Comparative performances of three specimens in the dissipation of energy of the experimental test results (a) and the results of numerical studies (b). 
In this study, the amount of energy dissipation in the specimen of the shear link is expressed by the area under cyclic hysteretic curves in terms of the force vs. displacement relationship. Calculate the area of hysteretic curve analysis is conducted using the incremental method where the curve is divided into small triangle. The amount of energy dissipation is the result of a cumulative sum of the total hysteretic curve generated in each stage of loading. Cumulative energy dissipation curve vs. displacement in the Figure 22a shows the amount of energy dissipation capacity of shear links due to cyclic loading.

From the experimental results showed that the shear link with diagonal stiffener $4.2 \mathrm{~mm}$ has the highest energy dissipation (Specimen III), while the link with 8 $\mathrm{mm}$ thick diagonal stiffener (Specimen I) in the early stages of loading is capable to achieve the highest energy dissipation among the three specimens, however, this specimen collapse in the early stage of loading. The failure is because of fracture occurred on the flange in the support.

The curve in Figure 22b is the result of numerical study. The curve indicates that the shear link with diagonal stiffener $8 \mathrm{~mm}$ (Specimen I) has the best performance in terms of energy dissipation. As shown in Figure $22 \mathrm{~b}$, the numerical result is slightly different with the experimental tests for Specimen I. This is because of the phenomenon of crack (fracture) occurred on the flange is difficult to model in the numerical studies.

Displacement ductility is defined as the ratio of the maximum displacement to the displacement at initial yield. Table 2 shows the values of yield displacement (dy), ultimate displacement (du) and the ductility of the experimental results. Information obtained from Table 2 that the Specimen III (shear link with 4.2 $\mathrm{mm}$ thick stiffeners) has the highest ductility, and Specimen II (shear link AISC standards) is lower whilst the Specimen I is the lowest ductility.

Table 2 Comparison of Displacement Ductility of the Specimens (Experimental Test Results).

\begin{tabular}{c|cc|cc|c}
\hline \multirow{2}{*}{ Specimen } & \multicolumn{2}{|c|}{ Yielding } & \multicolumn{2}{c|}{ Failure } & \\
\cline { 2 - 5 } & dy (mm) & Py (N) & du (mm) & Pu (N) & Ductility \\
\hline $\begin{array}{c}\text { DV8 } \\
\text { (spec.I) }\end{array}$ & -0.98 & $-111,208$ & -10.94 & $-521,517$ & 11.16 \\
$\begin{array}{c}\text { WS3 } \\
\text { (spec.II) }\end{array}$ & 1.5 & 120,839 & 25.38 & 310,409 & 16.92 \\
$\begin{array}{c}\text { DV42 } \\
\text { (spec.III) }\end{array}$ & -0.74 & $-119,840$ & $-16,58$ & $-457,681$ & 22.40 \\
\hline
\end{tabular}

Table 3 presents the value of yield, ultimate displacement and ductility resulting from numerical studies. Based on these results it was found that Specimen II 
(AISC standard shear link) has the highest ductility compared to the two other specimens and Specimens I (shear link with diagonal stiffener $8 \mathrm{~mm}$ ) had the lowest ductility.

Table 3 Comparison of Displacement Ductility of the Specimens (Numerical Analysis Results).

\begin{tabular}{c|cc|cc|c}
\hline \multirow{2}{*}{ Specimen } & \multicolumn{2}{|c|}{ Yielding } & \multicolumn{2}{c|}{ Failure } & \multirow{2}{*}{ Ductility } \\
\cline { 2 - 4 } & $\mathbf{P}_{\mathbf{v}}(\mathbf{N})$ & $\mathbf{d}_{\mathbf{v}}(\mathbf{m m})$ & $\mathbf{P}_{\mathbf{u}}(\mathbf{N})$ & $\mathbf{d}_{\mathbf{u}}(\mathbf{m m})$ & \\
\hline $\begin{array}{c}\text { DV8 } \\
\text { (spec.I) }\end{array}$ & 215,662 & 1.4 & 455,458 & 16.0 & 11.4 \\
$\begin{array}{c}\text { WS3 } \\
\text { (spec.II) }\end{array}$ & 164,856 & 1.6 & 285,675 & 23.5 & 14.5 \\
$\begin{array}{c}\text { DV42 } \\
\text { (spec.III) }\end{array}$ & 198,442 & 1.5 & 368,966 & 20.5 & 13.7 \\
\hline
\end{tabular}

Analysis of ductility parameters shows that it is difficult to compare between numerical and experimental results, especially in terms of determining the value of yield displacement. In the numerical studies the yield displacement is determined using the value of initial yield strain which occurred at one nodal point on the model in the vicinity of the support. The determination of initial yield in the experimental work is determined from the initial yield strain of the strain gage close to the support, although this strain gage is not located exactly in the same position at the nodal point in the numerical model. However, both results of the numerical studies and the experimental tests show very similar results that the shear link with thinner diagonal stiffener achieves higher displacement ductility.

\section{Conclusion}

Based on the results of numerical and experimental studies on the behavioral of shear link profile of WF steel representing Eccentrically Braced Frame system $(\mathrm{EBF})$, several conclusions can be drawn as follows:

a) The results of numerical studies show that the installation of diagonal stiffeners with a certain thickness on the web of WF profiles can improve the link performance in terms of strength, stiffness, displacement ductility, and energy dissipation. The vertical stiffener only improves the stability of the link but not the strength, stiffness, displacement ductility and energy dissipation of the shear link.

b) The experimental results showed that all three specimens have the same failure mode where the failure occurred in specimen are always initiated 
by the occurrence of cracks in the flange of WF profile close to the support.

c) Experimental tests of the three specimens showed that diagonal stiffener is significantly influenced the shear link performance. The initial failure along the weld of the flange of the profile at the vicinity of the support was observed with in-elastic strain even though this in-elastic strain still below the ultimate strain.

d) Comparison of the performance of each specimen carried out at 0.03 radians of in-elastic rotation where the three specimens were considered in-elastically stable before failure.

e) The best performance of the shear link in terms of strength, stiffness, displacement ductility and the cyclic energy dissipation is Specimen III with the thinness diagonal stiffener $(4.20 \mathrm{~mm})$ followed by Specimens II with no diagonal stiffener (AISC Standard) and Specimen I with $8,0 \mathrm{~mm}$ thick diagonal stiffener.

\section{Acknowledgements}

The Author and the co-Authors would like to express their gratitute and appreciation to The Research and Community Services Agency of ITB (LPPM ITB) which has funded this program through Structural Engineering Division of ITB under Research program 2009, contract no 077.A/K01.10/KP/2009 also Grant of Doctor Program of ITB No.418/K01.12/KU/2009.

\section{References}

[1] Popov, E.P., Recent Research on Eccentrically Braced Frames, Journal of Engineering Structures, 5(1), pp. 3-9, 1983.

[2] Moestopo, M. \& Aulia, M., Link Performance with Bolt Connection of EBF (In Indonesian), Association of Indonesian Structural Engineer Seminar, August, Jakarta, 2006.

[3] American Institute of Steel Construction, Seismic Provision for Structural Steel Buildings, AISC, Inc., 2005.

[4] Yurisman, Budiono, B., Mustopo, M. \& Suarjana, M., Numerical Analysis of the Shear Link Using Diagonal Web Stiffener of EBF Under Cyclic Loading (In Indonesian), Journal Teknik Sipil ITB,17(1), April 2010.

[5] Yurisman, Budiono, B., Mustopo, M. \& Suarjana, M., Parametric Study of the Shear Link of WF Profile Using Diagonal Web Stiffener of EBF Under Cyclic Loading (In Indonesian), National Conference of Post Graduate Program of Civil Engineering, Bandung, May 26, 2010

[6] Englekirk, R., Steel Structures: Controlling Behavior through Design, John Wiley and Son, Inc., 1994. 
[7] Yurisman, Budiono, B., Mustopo, M. \& Suarjana, M., The Behaviour of Shear Link with Diagonal Stiffener of EBF System (In Indonesian)", National Seminar on the Recent Development of the Usage of Steel Material in the World of Construction Industry, University of Parahyangan, Civil Engineering Faculty, Bandung, Indonesia, 2009.

[8] Yurisman, Budiono, B., Mustopo, M. \& Suarjana, M., The Improvement of the Shear Link Using Diagonal Web Stiffener of EBF Under Cyclic Loading (In Indonesian), Seminar and Exhibition of Indonesian Structural Engineer Association, Jakarta, August 8-9, 2009.

[9] Gobarah A. \& Ramadan.T., Seismic Analysis of Links of Various Lengths in Eccentrically Braced Frames, Can. Journal of Civ. Eng., 140-148, 1991.

[10] Engelhardt, M.D. \& Popov, E.P., Behavior of Long Links in Eccentrically Braced Frame. Report No. UCB/EERC-89/01. Berkeley: Earthquake Engineering Research Centre. University of California, 1989.

[11] Kasai K. \& Popov, E.P., General Behavior of WF Steel Shear Link Beams, Journal of the Structural Division. February, 112(2), 362-382. ASCE, 1986.

[12] Bruneau, M., Uang, C.M. \& Whittaker, A., Ductile Design of Steel Structures", McGraw-Hill, 1998. 